\title{
Should We Be Concerned about IB Research?
}

Mark Casson, University of Reading, UK

"Why do I feel so worried about the current state of international business studies?" That is the question I keep asking myself and am asking you now. I know that I shouldn't be asking this question. I feel guilty about it. I should be upbeat. I should be encouraging my colleagues and you. I should at least pretend to be optimistic for the good of the profession. Still, I ask you: Are you worried too? If so, What are you most worried about, and why?

What worries me? It isn't the subject itself. In IB, there is always something new that needs to be explained. It began with US investment in Europe, then Japanese investment in Asia, then European investment in the States; it continued with international joint ventures, the emergence of "emerging market multinationals," the growth of global supply chains in high-technology manufacturing, outsourcing, off-shoring $\mathrm{R} \& \mathrm{D}$, and the emergence of "world cities" with clusters of small innovative firms. Besides, globalization may be followed by de-globalization as political frictions and domestic discontents undermine international cooperation.

International business is even more exciting when you go backwards in time. The historical dimension of IB is truly fascinating. Its origins are lost in the mists of time - thousands of years ago. Records begin in the thirteenth century, with Italian merchant banks, Flemish textiles, English wool-growers, and so on. The chartered trading companies of the seventeenth century marked a great leap forward. The Industrial Revolution of the eighteenth century led to trade rivalry between Britain, the United States, and Germany in the nineteenth century, leading to two world wars in the twentieth century. The twenty-first century has witnessed the emergence of China as a world power. Despite "Donald Trump" and "Brexit," the number of countries actively promoting IB has never been higher in human history.

What worries me is that $I B$ research does not engage convincingly with these issues anymore. I came into IB by accident. I got a job at Reading in 1969—as an econometrician. It was only when Peter Buckley arrived in 1974 that I got interested in IB. Later, I studied railways and suddenly geography became important too. Then, I got interested in history, thanks mainly to Geoffrey Jones when he was my colleague at Reading.

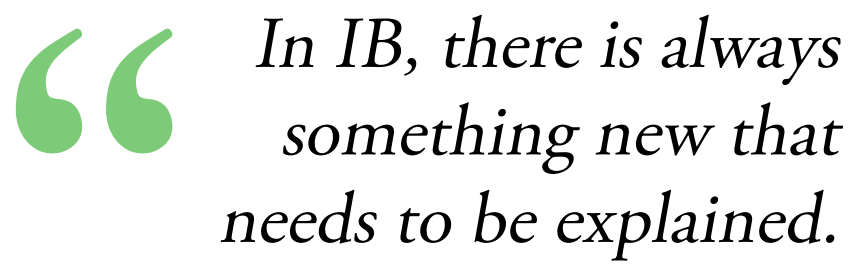

Basically, I wanted to find out how the global economy got to where it is today. The answer could be found, I thought, by integrating economics, econometrics, geography, and history. IB was the most promising field, it seemed, in which to locate such research. It was global, inter-disciplinary, young and ambitious-it was ideal!

I'm a "child of the sixties" so far as my education is concerned. At that time, there were "gold standards" in research. To be a professional economist, you had to understand general equilibrium theory. To be an econometrician, you had to understand the multivariate normal distribution and its properties, and simultaneous equation systems too. To be a geographer, you had to understand river systems, natural resources, demography, map projections, and so on. To be an historian, you had to know how to evaluate sources of evidence and synthesize evidence from different sources in a rigorous way. 
Every discipline had its gold standard. Being a professional was not just a question of qualifications on paper and letters after your name-it was a vocation to be taken very seriously! A qualified researcher should know the gold standard in his or her field and, as a serious scholar, should strive to attain it. In economics, the emphasis was on intellectual rigor, which translated into the need to develop an argument through a formal model. In statistics, it was a deep understanding of concepts such as probability, likelihood, randomness, sample, bias, confidence and power. History required a deep understanding, not only of sources, but mainly of the wider context in which historical actions took place.

\section{$\int(I B$ is an inherently complex subject, and no single discipline can therefore do it justice.}

My idea was this: $I B$ is an inherently complex subject, and no single discipline can therefore do it justice. But teams of experts working together could make progress quickly. What was needed was an integrated "systems view" of global business. The global system would be analyzed using methods that complied with a comprehensive gold standard-namely, intellectual rigor applied to the standards I mentioned before. As one of the most intellectually demanding fields of study, IB would integrate key disciplines to the very highest standards of scholarship.

Fast forward to today. There is no coherent systems view that commands general support in IB research. There are some experts but only a few. It is easier for disciplinary experts researching IB topics to publish in journals outside of IB than in IB journals themselves. A qualified economist submitting to an IB journal is liable to be told by referees that the concept of rational action is absurd and that mathematical models are pseudo-scientific constructs designed to legitimate a corrupt discipline (I'm speaking from experience here). The same with statistical methods. If you use the most appropriate statistical methods, you may be advised to use instead some "state of the art" business software package even though the algorithms in some of these packages do not even converge and, in consequence, the results they generate are often nonsense.

Data sources too are suspect. Many researchers use data collected by someone else for a very different purpose, and then impose their own interpretation on them. Data sources need to be val- idated-for example, it only takes a single misplaced keystroke to move a decimal point and skew the entire results. Regression results are highly sensitive to outliers but the way these results are reported in IB journals tends to disguise the problem. I could go on but I think the point is clear.

The most worrying feature of the modern scene, from my point of view, is that there is no gold standard for IB scholarship. There are merely conventions. You have to structure your paper in a specific way or you are told that "You don't know how to write a paper." You can't engage with the bigger picture because, if you do, you will be told "it's not research, it's just an essay." If you present a formal model, you'll be told that words would be better; as a concession, you may be allowed to stick it in an appendix. Indeed, the very idea of a gold standard is seen by many as "elitist" — who am I (or anyone else for that matter) to impose my personal standards on others? Intellectual rigor is a value-laden concept so why should IB scholars not strive for ambiguity or irony instead?

The lack of any gold-standard, it might be suggested, allows path-breaking research to flourish while imposing rigorous standards would inhibit creativity. No one has the right to set these standards anyway. And so on. Let me suggest, however, that creativity is not the outcome we have achieved. Anarchy is what you get when you have no standards, and anarchy, I suggest, is exactly what we have got. Careers in IB are advanced by coining new terms, inventing new concepts and even, in some cases, by hyping up results. Not all careers advance in this way, of course. But in terms of developing rigorous models, there seems to have been little progress at all in IB.

There is an alternative view, of course. Measured by the number of papers, IB research is flourishing. Record numbers of papers are submitted to leading IB journals. The cumulative stock of IB publications is enormous. We now know a whole lot more about IB than we did fifty years ago when IB first emerged as a distinctive field of study. Well, I agree that IB studies have grown in terms of quantity but the quality is highly debatable, as I have argued above. Do we really know more than we did fifty years ago, or do we just think that we do? How reliable is this knowledge that we think we possess?

When you read an article in a "four-star" journal, you are supposed to believe that it must be reliable. If an article in another four-star journal says the opposite, then you are expected to reconcile them somehow in your literature review. A possible explanation, of course, is that one of them is incorrect. The most plausible explanation, I suggest, is that actually both of them are incorrect! I find it impossible to believe that the referees acting for four-star journals are so expert in IB that they would be able to weed out every error. Checking every reference, every logical deduction, and every data point is hugely time-consuming. Indeed, in many cases the reviewer does not get to see the data and may not be able to access some of the references either. 
In some subjects, like medicine and law, it is crucial that research be correct - otherwise, people may die, be wrongly convicted or whatever. These disciplines have rigorous standards which are diligently enforced. I cannot help thinking that if the IB community were more concerned with the way its research is used, it would be more diligent in enforcing standards. Perhaps they think that no one uses their research or maybe they just can't be bothered.

One way of raising standards would be to encourage the replication of key results. Perversely, however, some journals discriminate against replication on the ground that such exercises lack originality. However, this assumes what ought to be provednamely, that the original research was indeed correct. Replication, it has been suggested, lacks "impact" but I would contest this view. A paper that demolishes previous research would attract a lot of interest and have considerable impact on future research, and, possibly, journal policy too. Opposition to replication, on the other hand, can be explained by vested interests-namely, the desire of leading scholars to protect their legacy. In my experience, journal editors can be very lenient towards established scholars whose work is later attacked by critics!

It seems to me that enforcing higher standards in IB would provoke debate and make the subject livelier. It would empower intellectual challengers and force the gate-keepers of orthodoxy to defend themselves. There would need to be standards of debate, of course, and debate would have to be open. History suggests a model here: historians still publish books which are reviewed in the pages of history journals, with authors having, in principle, a right of reply. The debate is public, reviewers are identified, and their reputation suffers if their review is unfair. Debate goes on in IB but mainly behind closed doors. The editorial boards of journals adjudicate in private between authors and reviewers. Crucial issues are resolved without the participation of the protagonists and without the knowledge of the wider readership.

I would like to believe that things will soon change for the better. After fifty years in which standards have eroded (in my opinion, that is), the next fifty years might reverse that trend and see standards increase. But I'm not convinced that it will happen. Our field needs a change in the way that IB departments recruit. It implies that people who have not trained as professional specialists in the disciplines mentioned above will start to recruit those who have. It implies that gate-keepers will throw open the gates to critics of previously published work. There are also many reasons for not making a change, and I know them well: "It won't be popular with students, because they don't like maths or economics, Business clients will hate it: they just want a simple message to take away, The IB group is already under threat: if we open up to other disciplines, then other departments will take away our jobs."
The alternative, however, could be even worse. I'm not the only person who holds the opinions I have set out, but I might be the only person inside the IB community who does although I doubt it. If the IB establishment doesn't change, then splinter groups may form. I have no reason to believe that this is imminent. But remember that sociology split off from economics about 1900, that international business split off from "business policy" about 1970, and that IB itself is currently split by functional area (marketing, HRM, finance, etc.). The unity of the IB community depends on everybody wanting to belong to it, yet we seem to live in a time, politically speaking, when everyone seems to want to go their separate ways! I'm sure that all of us in IB are "stronger together than apart," but professional specialists may well decide to go their own way unless academic standards are raised.

Now, the Big Questions for you: What do you think of my concerns? What is your diagnosis of "the state of IB research"? What other remedies would you suggest? Will you have to "retool" in order to engage in good IB research?

Please send me your answers and relevant comments through the AIB Insights website at https://aib.msu.edu/publications/ insights by April 30, 2019. I will reply to them in a subsequent issue of $A I B$ Insights.

\section{References}

Concerns about the direction taken by IB studies are nothing new; see:

Buckley, P. J. (Ed.). 2005. What is International Business? Basingstoke: Palgrave Macmillan.

To see what I mean by intellectual rigour you could look at my recent text:

Casson, M. 2016. The Theory of International Business: Economic Models and Methods. Basingstoke: Palgrave Macmillan.

Mark Casson (m.c.casson@reading.ac.uk) is Professor of Economics and Director of the Centre for Institutions and Economic History at the University of Reading, England. His recent publications include The Entrepreneur in History (with Catherine Casson, 2013) and The Multinational Enterprise: Theory and History (2018). He has just completed a book on Business and Community in Medieval Cambridge (with Catherine Casson, John Lee and Katie Phillips). 